[DRAFT VERSION: 23/09/2016]

\title{
Fine-tuning the IP Approaches for Fostering Open Science: Some Insights from India
}

\author{
Arul George Scaria and Rishika Rangarajan ${ }^{\dagger}$ \\ [Keywords: Open Science, Intellectual Property Rights, India, Global South]
}

Introduction

Science is the systematic enterprise of gathering knowledge about the universe and organizing and condensing that knowledge into testable laws and theories. The success and credibility of science are anchored in the willingness of scientists to:

1. Expose their ideas and results to independent testing and replication by others. This requires the open exchange of data, procedures and materials.

2. Abandon or modify previously accepted conclusions when confronted with more complete or reliable experimental or observational evidence. ${ }^{1}$

This definition of science, suggested by the American Physical Society, is one of the most comprehensive definitions, highlighting the importance of certain fundamental values in scientific research. The uniqueness of this definition is its ability to highlight those values in any discipline, including the ones that don't fall under disciplines traditionally considered as science. $^{2}$

Given the critical role of science in political, economic, social and technological development, we as a society need to introspect whether the current research practices reflect the fundamental norms of science. As Robert K Merton highlighted, there are four important norms that constitute the ethos of modern science- universalism, communism, disinterestedness and organised skepticism. ${ }^{3}$ One of the important common threads that connects all four major ethos emphasised

\footnotetext{
1 'What Is Science?' (American Physical Society, 14 November 1999)

<https://www.aps.org/policy/statements/99_6.cfm> accessed 18 September 2016.

${ }^{2}$ For an interesting discussion on what is science, Sundar Sarukkai, 'Defining Science', What Is Science? (1st edn, National Book Trust, 2012) 1-28.

${ }^{3}$ For details on these four norms, see Robert K Merton, 'The Normative Structure of Science', The Sociology of Science (University of Chicago Press 1979) 270-278.
}

\footnotetext{
${ }^{\dagger}$ Arul George Scaria is an Assistant Professor of Law and Co-Director of the Centre for Innovation, Intellectual Property and Competition (CIIPC), National Law University, Delhi. Rishika Rangarajan is a Research Fellow at the Centre for Innovation, Intellectual Property and Competition (CIIPC). We would like to thank Kuhuk Jain, Shreyashi Ray and Srishti Singhania for their insightful comments on the first draft. Views expressed are personal. Any comments or suggestions may be sent to arul.scaria@nludelhi.ac.in/rishika.rangarajan@nludelhi.ac.in.
} 
by Merton is openness. However, as illustrated in detail in the next section, this aspect is being compromised many a times, affecting the credibility of science. This crisis has led to the need for an intervention to regain the core values of science. Open science is an attempt in this regard wherein researchers from across the world, cutting across different disciplines, are increasingly getting a part of.

Some researchers fear that the primary beneficiaries of open science may not be the global south. Hence, we need to analyse the role of open science, its potential benefits and challenges in the global south. Another aspect to be looked at is how the intellectual property system in the global south approaches this issue. As both intellectual property rights (IPRs) as well as open science have important implications on the innovation eco-system, it is pertinent to identify the optimal balance between the two. This paper analyses these issues in the context of one of the countries in the global south - India. Though our primary focus is India, many of the discussions in this paper will be of relevance to other countries in the global south.

This introduction is followed by Section II, which examines in detail the current crisis in science. Section III introduces how open science emerged as a movement to counter this crisis. It also discusses the diverse benefits and challenges of practising open science. Section IV analyses the implications of open science for the global south. In this section, we also map the evolution of the open movements in India. In Section V, we discuss how the approaches towards IPRs could be modified to foster the open science movement in India. The article concludes by highlighting some areas for future research.

\section{Crisis in Science}

Science is going through a severe crisis. There is an increasing realisation amongst the scientific community that many of the research findings which are published in even the most prestigious journals cannot be replicated. ${ }^{4}$ Also, according to a recent survey conducted by Nature, more than seventy percentage of the researchers have failed to reproduce the findings of other researchers' experiments. ${ }^{5}$ This is one of the many indicators of the severity of the crisis.

We conceptualise this crisis as arising in two stages of research- production stage and consumption stage. Lack of transparency in research is one of the major challenges on the production side of research. This can be seen from a study regarding the transparency in clinical

\footnotetext{
${ }^{4}$ Florian Prinz, Thomas Schlange and Khusru Asadullah, 'Believe It or Not: How Much Can We Rely on Published Data on Potential Drug Targets?' (2011) 10 Nature Reviews Drug Discovery 712, 712-713.

${ }^{5}$ Monya Baker, '1,500 Scientists Lift the Lid on Reproducibility' (2016) 533 Nature 452, 453.
} 
trials. ${ }^{6}$ Similarly, lack of collaboration is also a serious issue, which is often leading to wastage of scarce resources. As noted by GPS Raghava, this is a particularly serious issue in the context of countries like India, with limited resources. ${ }^{7}$ The irony of this is that modern technologies offer better opportunities for collaborative research. ${ }^{8}$

Yet another important issue on the production side is lack of inclusiveness. Gender disparity is a serious crisis in most disciplines and participation of women in research is far below optimal levels. ${ }^{9}$ A recent study conducted by the National Science Foundation (NSF) shows that in the field of engineering, representation of women among the employed researchers and scientists is less than $20 \%{ }^{10}$ Similar is the issue of lack of inclusion of persons with disability. The NSF study cited above, reports that 1 in 9 scientists and engineers have a disability. ${ }^{11}$ Most of the disciplines and institutions are still seeing persons with disability only as consumers of information and not as producers of information. As highlighted by Moses Chowdary Gorrepati during one of our interviews, there is a systemic gap, right from the education stage, and science is neither inclusive nor disabled-friendly. ${ }^{12}$ Lack of representation results in lack of diversity in perspectives. In the Indian context particularly, the disparities could also reflect in terms of urban-rural divide, caste, class, etc.

In India, many scholars are also of the opinion that research is not given due importance. ${ }^{13}$ For example, Shamnad Basheer highlighted that research in law schools is not incentivised enough. ${ }^{14}$ Similarly, in the context of medical research, Arvind Kasthuri pointed out that research in India

\footnotetext{
${ }^{6}$ See generally, Jorge H Ramírez, 'Lack of Transparency in Clinical Trials: A Call for Action' (2013) 44 Colombia Médica : CM 243.

${ }^{7}$ Interview with GPS Raghava, Head, Bioinformatics Centre, CSIR Institute of Microbial Technology, Chandigarh (Chandigarh, 5 August 2016).

${ }^{8}$ Leanord Casutto, 'The Changing Face of Scientific Collaboration' (The Chronicle of Higher Education, 14 August 2016) <http://www.chronicle.com/article/The-Changing-Face-of/237451/> accessed 13 September 2016.

${ }^{9}$ Eileen Pollack, 'Why Are There Still So Few Women in Science?' The New York Times (3 October 2013) <http://www.nytimes.com/2013/10/06/magazine/why-are-there-still-so-few-women-in-science.html> accessed 13 September 2016.

10 'Employed Scientists and Engineers, by Occupation, Highest Degree Level, and Sex: 2013' <http://www.nsf.gov/statistics/2015/nsf15311/tables/pdf/tab9-5.pdf> accessed 12 September 2016.

11 'Women, Minorities, and Persons with Disabilities in Science and Engineering 2015' 14 <https://www.nsf.gov/statistics/2015/nsf15311/digest/nsf15311-digest.pdf> accessed 20 September 2016.

12 Interview with Moses Chowdary Gorrepati, Employability Trainer, EnAble India (Telephonic interview, 30 July 2016).

${ }^{13}$ For example, a study from the field of medical research shows that $57 \%$ of medical colleges in India had not published even a single research paper between 2005 and 2014. Dinesh C Sharma, 'Poor Research Output from India's Medical Schools' (2016) 387 The Lancet 28, 28.

${ }^{14}$ Interview with Shamnad Basheer, Founder, Spicy IP (Bangalore, 23 July 2016).
} 
is mainly publication driven, as opposed to an interest in solving a general researchable question. ${ }^{15}$ Moreover, there have been many reported cases of retractions due to fraud and plagiarism. ${ }^{16}$ All these factors are collectively contributing to quality issues in the production stage of research.

Similar challenges can be seen in the consumption stage of research. The most important challenge is with regard to accessibility of research outputs, in which two important issues need to be highlighted. The first one is existence of pay-walls around most research outputs. A recent study shows that 65 of the 100 most cited articles are behind pay-walls. ${ }^{17}$ Even the most liberally funded universities in the west are finding it difficult to subscribe to all journals. ${ }^{18}$ One can then imagine the situation of the libraries and researchers in the global south.

Even worse, is the case with regard to accessibility for persons with disability. Most countries don't have disability related exceptions within their copyright laws. ${ }^{19}$ Even though countries like India are now party to the Marrakesh Treaty, accessibility to all research outputs remains an unfulfilled dream for the disabled. Last, but not the least, there is a strong disconnect between science and society. Science is hierarchical, wherein citizens are perceived just as consumers of knowledge. ${ }^{20}$ As Anil K Gupta pointed out during an interview, there is an immense need for democratising science, the absence of which often results in research being disconnected from societal needs. ${ }^{21}$ According to him, there are various barriers preventing people from

\footnotetext{
${ }^{15}$ Interview with Arvind Kasthuri, Professor, Department of Community Health, St. Johns Medical College (Bangalore, 23 July 2016).

${ }^{16}$ See, for example, KS Jayaraman, 'Indian Science Adviser Caught up in Plagiarism Row' Nature (24 February 2012) <http://www.nature.com/doifinder/10.1038/nature.2012.10102> accessed 13 September 2016; Pushkar, 'In India, You Can Plagiarize and Flourish' (The Wire, 5 June 2015) <http://thewire.in/3307/in-india-you-canplagiarize-and-flourish/> accessed 13 September 2016; Jagdeep Singh Deep, 'Three Scientists Caught in Plagiarism Row, Top Publisher Retracts Article after 14 Years' The Indian Express (11 July 2016) $<$ http://indianexpress.com/article/india/india-news-india/thress-scientists-caught-in-plagiarism-row-top-publisherretracts-article-after-14-years-2905907/> accessed 13 September 2016.

17 '65 out of the 100 Most Cited Papers Are Paywalled.' (Authorea, 6 September 2016) <https://authorea.com/users/8850/articles/125400/_show_article> accessed 18 September 2016.

${ }^{18}$ Ian Sample, 'Harvard University Says It Can't Afford Journal Publishers' Prices' The Guardian (24 April 2012) <https://www.theguardian.com/science/2012/apr/24/harvard-university-journal-publishers-prices> accessed 13 September 2016.

${ }^{19}$ Marrakesh Treaty is intended to address this challenge. But as on 7 September 2016, only 20 countries have ratified the Marrakesh Treaty. See 'WIPO-Administered Treaties' (World Intellectual Property Organisation) <http://www.wipo.int/treaties/en/ShowResults.jsp?lang=en\&treaty_id=843> accessed 18 September 2016.

${ }^{20}$ See generally, Rolf Lidskog, 'Scientised Citizens and Democratised Science. Re-assessing the Expert-lay Divide' (2008) 11 Journal of Risk Research 69.

${ }^{21}$ Interview with Anil K Gupta, Professor, Indian Institute of Ahmedabad (Ahmedabad, July 1 2016). See, also,
} 
participating in science, and this includes institutional barriers, linguistic barriers, financial barriers and pedagogical barriers. ${ }^{22}$ The need of the time is scientised citizens and democratised science. $^{23}$

We view the crisis at the production stage and consumption stage as part of a vicious cycle, one influencing the other. Lack of access to the research outputs and research data will affect quality of research produced, prevent the possibilities of replication and also reduce transparency. Absence of inclusive participation and collaboration will reduce the diversity of perspectives, which in turn will also affect the quality of research. This includes failure to identify socially relevant research issues.

It is also important to view this crisis from the broader context in which research is produced. While it is easy to blame the scientists for the current crisis, it is also important to ask whether we can overlook the present incentive structure and how it contributes to the crisis. As Arvind Kasthuri noted in the context of medical research, research remains very publication oriented. ${ }^{24}$ This often forces researchers to chase attractive results and suppress negative or less desirable results. $^{25}$ The 'publish or perish' situation also leads to plagiarism, which is a particularly serious crisis in countries like India. ${ }^{26}$

'Useless Research - an Expensive Waste of Time?' The Guardian (13 July 2007)

<https://www.theguardian.com/science/blog/2007/jul/13/uselessresearchanexpensive> accessed 14 September 2016.

${ }^{22}$ Anil K Gupta highlighted this with the example of how buoyancy could be better taught by using cooking poori as an illustration. Such approaches may help in making science more accessible. Interview with Anil K Gupta.

${ }^{23}$ See generally, Rolf Lidskog, 'Scientised Citizens and Democratised Science. Re-assessing the Expert-lay Divide' (2008) 11 Journal of Risk Research 69.

${ }^{24}$ Interview with Arvind Kasthuri.

${ }^{25}$ Brian A Nosek, Jeffrey R Spies and Matt Motyl, 'Scientific Utopia II. Restructuring Incentives and Practices to Promote Truth Over Publishability' (2012) 7 Perspectives on Psychological Science 615, 617 and Hannah Devlin, 'Cut-Throat Academia Leads to "Natural Selection of Bad Science", Claims Study' The Guardian (21 September 2016) <https://www.theguardian.com/science/2016/sep/21/cut-throat-academia-leads-to-natural-selection-of-badscience-claims-study?CMP=share_btn_fb> accessed 22 September 2016.

${ }^{26}$ See, for example, Deepak Juyal, Vijay Thawani and Shweta Thaledi, 'Rise of Academic Plagiarism in India: Reasons, Solutions and Resolution' (2015) 32 Lung India : Official Organ of Indian Chest Society 542, 542; K Satyanarayana, 'Plagiarism: A Scourge Afflicting the Indian Science' (2010) 131 The Indian Journal of Medical Research 373, 373 and R Ramachandran, 'The Physics of Plagiarism' <http://www.frontline.in/static/html/fl1922/stories/20021108003508400.htm> accessed 14 September 2016. There is also a Wikipedia page which lists some instances of plagiarism in India - 'Scientific Plagiarism in India' $<$ https://en.wikipedia.org/w/index.php?title=Scientific_plagiarism_in_India\&oldid=738676735> accessed 18 September 2016. 
All this point towards a serious need for intervention in scientific research. Openness with regard to both acknowledgement of the crisis as well as the adoption of comprehensive solutions is extremely important. Open science is a global movement, which presents a plausible solution in this regard.

\section{Open Science as a Response to the Crisis in Science}

While many of the past 'open' movements like open access and open data have attempted to change the way knowledge is accessed and disseminated, not much attention has been given to the way scientific knowledge is produced. Many of the problems we highlighted in the previous section show the need for urgent interventions in the knowledge creation sphere and open science movement is a step in this regard.

In this context, it is important to understand what open science is and what its key characteristics are. While, there is a general consensus that open science is a movement aiming to open up science and bring in more transparency, there is no comprehensive definition. According to Michael Nielsen, "[o]pen science is the idea that scientific knowledge of all kinds should be openly shared as early as is practical in the discovery process. ${ }^{27}$ In the context of Horizon 2020 projects, the European Union has defined open science as "the way research is carried out, disseminated, deployed and transformed by digital tools, networks and media. It relies on the combined effects of technological development and cultural change towards collaboration and openness in research. Open science makes scientific processes more efficient, transparent and effective by offering new tools for scientific collaboration, experiments and analysis and by making scientific knowledge more easily accessible. ${ }^{, 28}$ Recently, in the Dakar Declaration, the signatories agreed that "[o]pen science is a means and not an end in itself and it is much more than just open access to publications or data; it includes many aspects and stages of research processes thus enabling full reproducibility and re-usability of scientific results. "29

In our survey on definitions of 'open science' as used in different disciplines, we came across more than thirty, each with its own contributions and characteristics. ${ }^{30}$ While the general

\footnotetext{
${ }^{27}$ Michael Nielsen, '[Open-Science] Definitions of Open Science?' (28 July 2011) <https://lists.okfn.org/pipermail/open-science/2011-July/000907.html> accessed 18 September 2016.

${ }^{28}$ European Commission, 'Open Science' (Digital Single Market, 19 April 2016) <https://ec.europa.eu/digitalsingle-market/en/open-science> accessed 18 September 2016.

29 'Dakar Declaration on Open Science in Africa' (March 2016) < http://www.sci-gaia.eu/dakar-declaration/> accessed 17 September 2016.

${ }^{30}$ We have tried to map the key characteristics highlighted in each of those definitions and the data in this regard is accessible at
} 
understanding is that it encompasses the prior open movements such as open access, open data, etc., open science goes beyond these movements to address the more fundamental problems with the global scientific inquiry.

A broad and inclusive definition, that can retain the flexibilities required to cover diverse disciplines, can make enormous differences to the discussions and debates surrounding this movement. Without a common language, particularly for a term with several different connotations, there can be challenges for policy changes. ${ }^{31}$ In this regard, based on the key characteristics of existing definitions of open science, as used in different fields and by different scholars, we have attempted to evolve a more comprehensive definition:

Open science broadly refers to scientific inquiries wherein the characteristics of openness, collaboration, transparency, availability, accessibility, replicability, constant and continuous transfer of knowledge between producers and users of knowledge, prioritisation of research and innovation based on social needs, and non-existencel minimal existence of IP restrictions are perceptible and exist throughout all stages of research. ${ }^{32}$

Since the terms used in our definition have been used several times in several definitions, it is pertinent to understand how we have characterised these terms. The term 'open science' is inclusive, encompassing all the 'open' movements like open access to scholarly publications, open data, open lab notes and open research tools.

'Transparency' in the context of our definition means transparency in methodology, research tools, research data and generation/ communication/ presentation of results. Transparency in scientific communication is extremely important as it enables reproducibility. ${ }^{33}$ Secrecy and opacity are against the basic tenets of science. ${ }^{34}$

<https://docs.google.com/spreadsheets/d/1FcoBGUmtZKbEcnsvxBTOYO1FasoMLuGueOZ8_iy_RX0/edit\#gid=0> accessed 18 September 2016.

31 Michael Clemens, 'A Clear Distinction Is Needed between Replication Tests and the Evaluation of Robustness in Social Science Literature' <http://blogs.lse.ac.uk/impactofsocialsciences/2015/04/15/the-meaning-of-replicationand-robustness/> accessed 14 September 2016 and Thomas Leeper, 'What's in a Name? The Concepts and Language of Replication and Reproducibility' (12 May 2015) <http://thomasleeper.com/2015/05/open-sciencelanguage/> accessed 14 September 2016.

${ }^{32}$ For more details on the definitions that we relied upon to develop our own definition see <https://docs.google.com/spreadsheets/d/1YJzHX6_ERhjh4mW41iJDZi3kLdHW7VZmXlpx7A4fxUI/edit\#gid=0> 18 September 2016.

${ }^{33}$ Story V Landis and others, 'A Call for Transparent Reporting to Optimize the Predictive Value of Preclinical Research' (2012) 490 Nature 187, 187-190.

${ }^{34}$ David Inglis, John Bone and Rhoda Wilkie, Nature: Reconfiguring the Social (Taylor \& Francis 2005) 89. 
'Accessibility' has two important elements - first, availability in online/digital formats at marginal costs, and second, accessibility in terms of disabled friendly scientific inquiry. Though many people use availability and accessibility interchangeably, it is important to note that not all available data is necessarily accessible. For instance, data made available by many researchers may not be in usable formats, hence failing the 'accessibility' requirement. Moreover, as stated before, science is still viewing disabled persons only as consumers of information and not as producers of information. ${ }^{35}$ The barrier to participation emerges at the education level and continues to exist till the point of dissemination of research. ${ }^{36}$ It is important for science to address these practical hurdles to enable representation and participation of persons with disabilities.

Finally, the term 'open data' in the context of open science includes availability and accessibility of data for reuse and redistribution, particularly through integration and connection of data as well as proper metadata. This implies that the data from any research should be published immediately on its generation or as early as is practical.

It is also important to see the benefits as well as the challenges of practising open science. While it is difficult to quantify the benefits, they can be broadly categorised into five clusters - better research, better research processes, benefits to the scientific community, societal benefits, and economic benefits.

The first and most important is better research. By making all the research publicly available, it increases public scrutiny and as a result, it also increases the chances of errors being found. ${ }^{37}$ Ironically, this is also one of the reasons why all scientists may not embrace open science. For example, during one of our interviews, GPS Raghava highlighted that one of the reasons for the lack of momentum towards open science in India is the lack of confidence among scientists in their own research. ${ }^{38}$

\footnotetext{
${ }^{35}$ This issue was also highlighted by Swaraj Paul Barooah in one of our interviews. Interview with Swaraj Paul Barooah, Executive Vice-President, IDIA (Bangalore, 21 July 2016).

${ }^{36}$ Interview with Moses Chowdary Gorrepati.

37 Jelte M Wicherts, Marjan Bakker and Dylan Molenaar, 'Willingness to Share Research Data Is Related to the Strength of the Evidence and the Quality of Reporting of Statistical Results' (2011) 6 PLOS ONE e26828, 1-7; Stephanie E Hampton and others, 'The Tao of Open Science for Ecology' (2015) 6 Ecosphere 1, 2; and Erin C McKiernan and others, 'How Open Science Helps Researchers Succeed' (2016) 5 eLife e16800, 10-11.

${ }^{38}$ Interview with GPS Raghava.
} 
Open science also allows various perspectives to be drawn from the same research which may encourage new ideas. ${ }^{39}$ Several people from different backgrounds and fields looking at the same research enable identification of new research questions. ${ }^{40}$ Openness therefore not only facilitates more research, but facilitates more quality research. ${ }^{41}$ Recognizing and breaking the inherent flaws in the closed peer review system can also improve the quality. ${ }^{42}$ The foundation of science rests on verifiability, and open science helps in verifiability through more scrutiny. ${ }^{43}$

Second, open science also contributes to better research processes by increasing the efficiency of the scientific inquiry method, both in terms of cost as well as effort. Open access to research outputs can lower the cost of research. ${ }^{44}$ Additionally, collaborations allow the possibility of using the same resources, including data and scientific tools for multiple purposes. ${ }^{45}$ Open science values collaborations within the science community, among the disciplines and also between the community and society, thus allowing for more efficient use of resources.

The third cluster of benefits pertains to how open science benefits the scientific community as a whole. It is observed that with openness, researchers gain citation advantage. ${ }^{46}$ Openness also

\footnotetext{
${ }^{39}$ Ann Grand and others, 'On Open Science and Public Engagement with Engineering' (European Association for Studies in Science and Technology, Trento, Italy, 1-4 September 2010) 6 <http://eprints.uwe.ac.uk/1354> accessed 18 September 2016.

40 Angus Whyte and Graham Pryor, 'Open Science in Practice: Researcher Perspectives and Participation' (2011) 6 International Journal of Digital Curation 199, 202.

${ }^{41}$ Sascha Friesike and others, 'Opening Science: Towards an Agenda of Open Science in Academia and Industry' (2014) 40 The Journal of Technology Transfer 581, 597.

42 RIN and NESTA, Open to All? Case Studies of Openness in Research (Research Information Network, September 2010) 12 〈http://www.rin.ac.uk/system/files/attachments/NESTA-RIN_Open_Science_V01_0.pdf> accessed 18 September 2016 and Richard Smith, 'Peer Review: A Flawed Process at the Heart of Science and Journals' (2006) 99 Journal of the Royal Society of Medicine 178, 179.

${ }^{43}$ OECD, 'Making Open Science a Reality' [2015] (OECD Science, Technology and Industry Policy Papers No. 25) $10<$ http://dx.doi.org/10.1787/5jrs2f963zs1-en > accessed 17 June 2016.

${ }^{44}$ See generally, Susan Mayor, 'Open Access Could Reduce Cost of Scientific Publishing' (2004) 328 British Medical Journal 1094.

${ }^{45}$ Interview with Jayant Murthy, Senior Professor, The Indian Institute of Astrophysics, Bangalore (Bangalore, July 21 2016).

${ }^{46}$ For example, one of the studies shows two fold increase in citations when an article is shared through ArXiv. See Travis S Metcalfe, 'The Rise and Citation Impact of Astro-Ph in Major Journals' [2005] Bulletin of American Astronomical Society 555, 555-557, <http://arxiv.org/abs/astro-ph/0503519> accessed 13 September 2016. However, some studies show that citation advantages can vary with disciplines. For example, McVeigh shows that citation advantage exists for medicine, engineering, physics and mathematics, while it wasn't perceptible in the fields of life sciences and chemistry. See Marie E McVeigh, 'Open Access Journals in the ISI Citation Databases: Analysis of Impact Factors and Citation Patterns: A Citation Study from Thomson Scientific' $7<$ http://ipscience.thomsonreuters.com/m/pdfs/openaccesscitations2.pdf $>$ accessed 13 September 2016. Some scholars argue
} 
provides opportunities to signal one's own skill sets to external parties, which in turn may induce more collaboration. $^{47}$

The fourth important facet of open science is its probable impact on the society. Open science can strengthen the relationship between science and society by increasing awareness of community needs, public engagement, and transfer of knowledge to the society. ${ }^{48}$ Scholars like Anil K Gupta also consider open science as a prelude to a more rational society. ${ }^{49}$ Open science can also improve the scientific literacy of the public. ${ }^{50}$ With more scientific engagement with citizens, better and more relevant research may emerge, which in turn will contribute to a better relationship between science and society.

The final cluster of benefits relate to the long term effects of open science on the economy. Besides encouraging optimal use of scarce resources, open science can increase the economic and social impact of research, foster economic growth, and induce knowledge spillovers. ${ }^{51}$ Open

that the citation advantages could also be attributed to other factors such as quality bias, as researchers may publish only their best works through open access modes. See, for example, OECD, 'Making Open Science a Reality' [2015] (OECD Science, Technology and Industry Policy Papers No. 25) 24 <http://dx.doi.org/10.1787/5jrs2f963zs1 en > accessed 17 June 2016.

47 Simcha Jong and Kremena Slavova, 'When Publications Lead to Products: The Open Science Conundrum in New Product Development' (2014) 43 Research Policy 645, 645.

${ }^{48}$ See generally, Ann Grand and others, 'Open Science: A New “Trust Technology”?' (2012) 34 Science Communication 679; OECD, 'Making Open Science a Reality’ [2015] (OECD Science, Technology and Industry Policy Papers No. 25) 18-19 <http://dx.doi.org/10.1787/5jrs2f963zs1-en > accessed 17 June 2016; and William K Michener and Matthew B Jones, 'Ecoinformatics: Supporting Ecology as a Data-Intensive Science' (2012) 27 Trends in Ecology \& Evolution 85, 91.

${ }^{49}$ Interview with Anil K Gupta. Citing the example of the mass hysteria created by certain religious leaders in India, he pointed out that with open science and constant communication between science and society, more rationality can be brought into the society.

${ }^{50}$ Sarah Currier, Open Science Project: Final Report (Centre for Research Communications, University of Nottingham 2011) 14 <http://www.retawprojects.com/uploads/OpenScience_Report-Sarah_Currier.pdf>accessed 17 September 2016.

51 RIN and NESTA, Open to All? Case Studies of Openness in Research (Research Information Network, September 2010) 11 <http://www.rin.ac.uk/system/files/attachments/NESTA-RIN_Open_Science_V01_0.pdf> accessed 18 September 2016; Sarah Currier, Open Science Project: Final Report (Centre for Research Communications, University of Nottingham 2011) 4 <http://www.retawprojects.com/uploads/OpenScience_ReportSarah_Currier.pdf> accessed 17 September 2016.; Paul A David 'The Economic Logic of 'Open Science' and the Balance between Private Property Rights and the Public Domain in Scientific Data and Information: A Primer' in National Research Council, The Role of Scientific and Technical Data and Information in the Public Domain: Proceedings of a Symposium (The National Academies Press 2003) 19 -33 and Rep. Jim Sensenbrenner, 'Give The Public What It Pays For: Scientific Research’ Forbes (10 June 2016) <http://www.forbes.com/sites/realspin/2016/09/06/give-the-public-what-it-pays-for-scientific-research/> accessed 17 September 2016. 
science institutions may also provide alternatives to IPRs, which are generally used to address certain market failures. ${ }^{52}$ For example, Zakir Thomas discussed the importance of open science in the context of developing drugs for neglected and rare diseases, wherein IPR has failed to provide incentives for research and development (R\&D). ${ }^{53}$ Finally, it can also foster innovation and creativity in the economy. ${ }^{54}$

While the benefits of open science are numerous and far reaching, there are also some practical and implementation challenges, existing at both individual as well as institutional level, that need to be addressed. This includes issues relating to costs, existing mindset, information overload, and lack of incentives within the current research eco-system.

Setting up infrastructures able to implement open science principles in full requires investment, both in terms of time and money. It might require new infrastructures or modifications in the existing infrastructures. ${ }^{55}$ In several countries, the implementation of open science may have to start with the very basic step of getting proper internet access or even electricity. In some, it might have to start with setting up repositories or providing adequate training programs for researchers. ${ }^{56}$ Dissemination of research outputs openly may also involve substantial costs. For example, many of the open access journals impose article processing charges (APCs) which may not be affordable for many researchers, particularly those from the global south. One study that has analysed 1370 journals listed in Directory of Open Access Journals (DOAJ) shows that the APCs vary between USD 8 and USD 3900..$^{57}$

\footnotetext{
${ }^{52}$ See generally, Paul A David 'The Economic Logic of 'Open Science' and the Balance between Private Property Rights and the Public Domain in Scientific Data and Information: A Primer' in National Research Council, The Role of Scientific and Technical Data and Information in the Public Domain: Proceedings of a Symposium (The National Academies Press 2003) 19-33.

${ }^{53}$ Interview with Zakir Thomas, Former Project Director, Open Source Drug Discovery (New Delhi, 6 July 2016).

${ }^{54}$ For example, some of the oil companies have started sharing data to help them solve complex problems. See David Hunn, 'Oil Companies Joining Open Source World by Sharing Data' $<$ http://fuelfix.com/blog/2016/08/25/oilcompanies-joining-open-source-world-by-sharing-data/> accessed 17 September 2016; Peter Krakerand others, 'The Case for an Open Science in Technology Enhanced Learning' (2011) 3 International Journal of Technology

Enhanced Learning 643, 649; and Sarah Currier, Open Science Project: Final Report (Centre for Research Communications, University of Nottingham 2011) $4<$ http://www.retawprojects.com/uploads/OpenScience_ReportSarah_Currier.pdf $>$ accessed 17 September 2016.

55 Kaja Scheliga and Sascha Friesike, 'Putting Open Science into Practice: A Social Dilemma?' (2014) 19 First Monday <http://firstmonday.org/ojs/index.php/fm/article/view/5381> accessed 20 September 2016.

${ }^{56}$ As Jayant Murthy pointed out, many scientists may find it difficult to adopt new programmes and technologies and this can act as an impediment to open science. Interview with Jayant Murthy.

${ }^{57}$ David J Solomon and Bo-Christer Björk, 'A Study of Open Access Journals Using Article Processing Charges' (2012) 63 Journal of the American Society for Information Science and Technology 1485, 1488.
} 
Another related challenge is breaking the misconceptions and fears regarding openness in science, which manifest in several ways. An inherent feeling of ownership over research resources and outputs creates a fear of free-riding among many scientists. ${ }^{58}$ This in turn results in a general reluctance to share research and data openly. ${ }^{59}$ A study on data sharing among the genomic research community shows that many researchers are also of the belief that as creators of data, they must be able to complete all research based on their data before others. ${ }^{60}$ They tend to believe that they can share data publicly only when all potential publications are derived from the data. ${ }^{61}$ Some scientists also think that spending time on sharing their research outputs through non-traditional channels takes time away from their "real" work. ${ }^{62}$ For example, in the context of genomic research data sharing, lack of time to do the required quality management before uploading data was considered by many respondents as an important factor dissuading them from sharing data. ${ }^{63}$ Underlying all these issues could be the prevalent feeling of insecurity, competitiveness, ownership, and ego. ${ }^{64}$

Current incentive structures in science and academics are also problematic. As mentioned earlier, research remains extremely publication driven. ${ }^{65}$ Particularly, publications in high-impact

\footnotetext{
${ }^{58}$ This issue was also highlighted by many scholars including Jayant Murthy and Arvind Kasthuri during our interviews. Interview with Jayant Murthy and interview with Arvind Kasthuri. See, also, Kaja Scheliga and Sascha Friesike, 'Putting Open Science into Practice: A Social Dilemma?' (2014) 19 First Monday <http://firstmonday.org/ojs/index.php/fm/article/view/5381> accessed 20 September. 2016.

${ }^{59}$ Interview with Jayant Murthy and Kaja Scheliga and Sascha Friesike, 'Putting Open Science into Practice: A Social Dilemma?' (First Monday, 2014) <http://firstmonday.org/ojs/index.php/fm/article/view/5381> accessed 17 September 2016.

${ }^{60}$ Arul George Scaria, Arianna Broggiato and Tom Dedeurwaerdere, Report on the IP Model Agreements for Precompetitive Access to Microbial Genomic Research Databases, 22

<https://www.microb3.eu/sites/default/files/deliverables/MB3_D8_4_PU.pdf> accessed 13 September 2016. ${ }^{61}$ Ibid.

${ }^{62}$ Ann Grand and others, 'Mapping the Hinterland: Data Issues in Open Science' (2016) 25 Public Understanding of Science 88, 90.

${ }^{63}$ Arul George Scaria, Arianna Broggiato and Tom Dedeurwaerdere, Report on the IP Model Agreements for Precompetitive Access to Microbial Genomic Research Databases, 22 <https://www.microb3.eu/sites/default/files/deliverables/MB3_D8_4_PU.pdf> accessed 13 September 2016. ${ }^{64}$ These issues were highlighted during our interviews by different scholars like Arvind Kasthuri, CNR Rao, GPS Raghava and Zakir Thomas. Interview with Arvind Kasthuri; interview with CNR Rao, National Research Professor, Jawaharlal Nehru Centre for Advanced Scientific Research, Bangalore (Bangalore, 22 July 2016); interview with GPS Raghava and interview with Zakir Thomas.

${ }^{65}$ For example, in the Indian context, appointments and promotions in public funded colleges and universities are guided by the Academic Performance Index (API) developed by the University Grants Commission (UGC). API places high reliance on the number of publications. See University Grants Commission (Minimum Qualifications for Appointment of Teachers and other Academic Staff in Universities and Colleges and Measures for the Maintenance of Standards in Higher Education) (4th Amendment), Regulations, 2016
} 
journals play an important role in the career progress of researchers. ${ }^{66}$ Adopting principles of open science in research is not yet considered as an important evaluative criteria for the assessment of researchers and research outputs. ${ }^{67}$

Finally, open science may also lead to information overload and information misuse. With more openness, more data and more publications will be available for public consumption. How this additional information would be processed by the public is still an issue to be addressed. In this context, some scholars also underline the possible misuse of information. This includes, the potential misuse for terrorism related activities or self treatment solely based on limited information. ${ }^{68}$ However, a counter argument would be that the issue of information overload and misuse has been raised with every technological development with regard to dissemination of information, including the print press. ${ }^{69}$

On an overall analysis of the benefits and challenges, one can conclude that the potential benefits outweigh the challenges. More importantly, as Shamnad Basheer pointed out, the pertinent question to be asked is whether the society would be better off without open science. ${ }^{70}$ In the absence of open science, we would only become more closed, selfish, hierarchical, and unequal as a society. ${ }^{71}$ If we want to push the notions of democracy, equality, and egalitarianism, then openness should be the core value. ${ }^{72}$

\section{Practising Open Science in the Global South}

While open science is considered to be beneficial in general, it is important to recognise that there are specific challenges with regard to its implementation in the global south. For example, practising open science requires infrastructure, provision and maintenance of which is

<http://www.ugc.ac.in/pdfnews/3375714_API-4th-Amentment-Regulations-2016.pdf> accessed 18 September 2016.

${ }^{66}$ Eugenie Samuel Reich, 'Science Publishing: The Golden Club’ (2013) 502 Nature 291, 291.

67 Kaja Scheliga and Sascha Friesike, 'Putting Open Science into Practice: A Social Dilemma?' (2014) 19 First Monday <http://firstmonday.org/ojs/index.php/fm/article/view/5381> accessed 20 September 2016.

${ }^{68}$ See generally, Brian J Gorman, 'Balancing National Security and Open Science: A Proposal for Due Process Vetting ThinkPiece' (2004) 7 Yale Journal of Law and Technology 491. See also, Patty Kostkova and others, 'Who Owns the Data? Open Data for Healthcare' (2016) 4 Digital Health 1, 3.

${ }^{69}$ Ann Blair, 'Information Overload's 2,300-Year-Old History' < https://hbr.org/2011/03/information-overloads2300-yea> accessed 17 September 2016.

${ }_{71}^{70}$ Interview with Shamnad Basheer.

${ }^{71}$ Ibid.

${ }^{72}$ Ibid. 
expensive. $^{73}$ Countries in the global south may not have adequate funding set aside for research. ${ }^{74}$ Similarly, some countries may even have challenges regarding access to computer or internet. ${ }^{75}$ For open science to sustain, it is important to contextualise its implementation based on the local needs and problems. ${ }^{76}$

It has been argued that the present global structures favour the northern researchers. ${ }^{77}$ Very often, practices and experiences of the global north are imposed on the global south, which may not be relevant, and may even be harmful in some situations. ${ }^{78}$ The existing power structures may even prioritise certain forms of knowledge and research over others, where northern knowledge is seen as "most legitimate". 79 Subbiah Arunachalam referred to this as the "Harvard Hyderabad Syndrome', wherein science performed in the south is seen as meagre or not worthy of notice. ${ }^{80}$

Another argument is that the countries in the global south may not be able to derive the benefits of openness to the same extent as those in the global north. ${ }^{81}$ As Jaykumar Menon highlighted, people in power and people with resources may have more capabilities to excel using openness. ${ }^{82}$ However, he also noted that this just implies the need to develop capacities necessary to ensure a successful open science environment. ${ }^{83}$ If that is ensured, an open model is beneficial for countries with lesser affordability. ${ }^{84}$ Similarly, other scholars have argued that it is important for

${ }^{73}$ Kaja Scheliga and Sascha Friesike, 'Putting Open Science into Practice: A Social Dilemma?' (2014) 19 First Monday <http://firstmonday.org/ojs/index.php/fm/article/view/5381> accessed 20 September 2016.

74 Jennifer I Papin-Ramcharan and Richard Dawe, 'Open Access Publishing: A Developing Country View' (2006)

11 First Monday <http://firstmonday.org/ojs/index.php/fm/article/view/1332> accessed 20 September 2016.

${ }^{75}$ Kevin Zelnio, 'Bandwidth and Open Access in Developing Countries' (Scientific American, September 2012) <http://blogs.scientificamerican.com/evo-eco-lab/bandwidth-and-open-access-in-developing-countries/> accessed 17 September 2016.

${ }^{76}$ Becky Hillyer, 'Uncovering the Challenges of Open Science in Development' (OCSDNet, 2016) $<$ http://ocsdnet.org/uncovering-the-challenges-of-open-science-in-development/> accessed 17 September 2016.

77 Ibid.

${ }^{78}$ For a detailed discussion on this issue, ibid.

${ }^{79}$ Ibid. In the Indian context, scholars like Sarukkai have pointed out that the general belief that science from the west is more important has contributed to the invisibility of Indian science. Sarukkai (n 2) 49.

${ }^{80}$ Interview with Subbiah Arunachalam, Distinguished Fellow, Centre for Internet and Society (Bangalore, 22 July 2016).

${ }^{81}$ For example, in the context of environmental research data, it was highlighted that developing countries may remain mere data providers, with countries with more resources enjoying the actual benefits of shared data. See generally, Eduardo Eiji Maeda and Juan Arevalo Torres, 'Open Environmental Data in Developing Countries: Who Benefits?' (2012) 41 Ambio 410.

${ }^{82}$ Interview with Jaykumar Menon, ISID Professor of Practice, Mcgill University (Telephonic Interview, 13 August 2016).

83 Ibid.

${ }^{84}$ Ibid. 
countries like India to start competing in the global market, and artificial boundaries cannot be used to justify a closed scientific inquiry. ${ }^{85}$

Despite the clear need for openness, India is yet to see a sustainable open science movement. As Anil K Gupta pointed out, it is an interesting paradox that despite the greater need for openness in the global south, it is the global north that is often more open. ${ }^{86}$ According to him, India remains a downloading nation, rather than an uploading nation, when it comes to information sharing. ${ }^{87}$

There have been very few open science movements and projects in India that have adopted open science principles. Open Knowledge Foundation Network (now Open Knowledge International) had initiated an open science project titled 'VITAYARD', an open platform for researchers to share their research outputs. ${ }^{88}$ The Open Source Drug Discovery Project, an initiative of the Council of Scientific and Industrial Research (CSIR), was also cited by some scholars as an open science project. ${ }^{89}$ Ganit Labs in Bangalore, a research lab working in the area of Genome science, also asserts that they are adopting open science principles. ${ }^{90}$ It is important to note that during our interviews, we had specifically asked our interviewees to provide an example of an open science project in India, as per their characterisation of the term. Interestingly, many of the interviewees were unable to provide even one example.

Among all the open movements, open access has gained the maximum momentum in India. The movement was pioneered by some of the top institutions like Indian Institute of Science, MS Swaminathan Research Foundation, and Indian Statistical Institute. ${ }^{91}$ These movements led to the setting up of institutional repositories such as Librarian's Digital Library in Indian Statistical

\footnotetext{
${ }^{85}$ Interview with Jayant Murthy and interview with Swaraj Paul Barooah.

${ }^{86}$ Interview with Anil K Gupta.

87 Ibid.

${ }^{88}$ However, the blog has not been updated since 2014. See 'Vitayard: Science Vitality Platform' <https://vitayard.wordpress.com/> accessed on 18 September 2016.

${ }^{89}$ Interview with Jaykumar Menon; interview with Phet Sayo, Senior Program Officer, International Development Research Centre (New Delhi, 25 August 2016); and interview with Anindya Chatterjee, Regional Director, Asia, International Development Research Centre (New Delhi, 2 August 2016).

${ }^{90}$ For more information see 'Ganit Labs'<http://www.ganitlabs.in/open-science> accessed on 18 September 2016.

91 Subbiah Arunachalam and Madhan Muthu, Open Access to Scholarly Literature in India-A Status Report (with Emphasis on Scientific Literature) (Centre for Internet and Society 2015) $25<\mathrm{http}$ ://editors.cisindia.org/openness/publications/open-access-scholarly-literature.pdf> accessed 15 September 2016.
} 
Institute, Bangalore. ${ }^{92}$ Currently, more than 300 open access journals from India are listed in the Directory of Open Access Journals. ${ }^{93}$

There have also been some policy initiatives from the government. The Indian Council of Agricultural Research (ICAR) released their open access policy in $2013 .{ }^{94}$ This policy mandates all ICAR institutes to set up open access repositories and all researchers to deposit their final research works at these repositories. ${ }^{95}$ This was followed by the release of a joint open access policy by the Department of Biotechnology and the Department of Science \& Technology in 2014. ${ }^{96}$ This policy provides that all papers resulting from DBT/DST funding must be submitted either to the institutional repository or the central repository, in case the former isn't set up. ${ }^{97}$ Recently, the state of Tamil Nadu, also mandated that publications from all government departments and Tamil University be released under the Creative Commons license. ${ }^{98}$ The last decade has also seen several events aimed at increasing awareness about open access. ${ }^{99}$ However, as Subbiah Arunachalam pointed out, while institutions are taking steps, the level of compliance remains very poor. ${ }^{100}$

\footnotetext{
92 Sarika Sawant, 'Past and Present Scenario of Open Access Movement in India' (2013) 39 The Journal of Academic Librarianship 108, 108.

${ }^{93}$ DOAJ, 'Directory of Open Access Journals'<https://doaj.org/search> accessed 18 September 2016.

${ }^{94}$ Indian Council of Agricultural Research (ICAR) Open Access Policy 2013 <http://icar.org.in/en/node/6609> accessed 16 September 2016.

${ }^{95}$ Ibid.

${ }^{96}$ DBT and DST Open Access Policy: Policy on Open Access to DBT and DST Funded Research 2012 <http://www.dbtindia.nic.in/wp-content/uploads/APPROVED-OPEN-ACCESS-POLICY-DBTDST12.12.2014.pdf〉 accessed 19 September 2016.

${ }^{97}$ Ibid 1-2.

${ }^{98}$ For a copy of the order in Tamil, see <https://upload.wikimedia.org/wikipedia/commons/b/b9/GoTN_Tamil_Development_Departments_order_on_creati ve_commons_cc_by_sa.pdf.> accessed on 18 September 2016. For a rough English translation of the order, see $<$ https://docs.google.com/a/nludelhi.ac.in/document/d/1F9-s5Eh7auCbH_zUfmXR9ZlrVjtDvo2UlDztfxSVM/edit?usp=drive_web> accessed on 18 September 2016.

${ }^{99}$ See, for example, 'Seminar on Open Access in Research Area: A Strategic Approach' (TERI) $<$ http://www.teriin.org/eventdocs/agenda/open-access-agenda.pdf > accessed on 17 September 2016; 'Looking Backward and Moving Forward: Open Access Movements at a Crossroads' (TERI) <http://www.teriin.org/eventdocs/files/Open-Access\%20flyer-agenda.pdf> accessed on 17 September 2016; 'Opening up by Closing the Circle: Strengthening Open Access in India' (UNESCO, JNU \& CEMCA) $<$ http://nkc.ac.in/uploaded_files/Conference\%20Report-UNESCO-JNU-CEMCA-Santosh\%20C\%20Hulagabali2013.pdf $>$ accessed on 17 September 2016 and 'Consilience: A Conference on Open Access and IP' (NLS Bangalore) < http://www.consilience-nls.com> accessed on 17 September 2016.

${ }^{100}$ Interview with Subbiah Arunachalam.
} 
Open data, on the other hand, has received lesser attention and the relevant movements have been primarily limited to government data. In 2012, the Government of India launched the Open Government Data platform along with the National Data Sharing and Accessibility Policy 2012. ${ }^{101}$ The policy highlights important principles of data sharing such as openness, sustainability, transparency, privacy, etc. ${ }^{102}$ It aims to facilitate access "to all sharable nonsensitive data available either in digital or analog forms but generated using public funds by various Ministries/ Departments/Subordinate offices/ Organizations/ Agencies of Government of India. ",103

However, India is yet to see a strong movement with regard to openness in research data. Even most of the leading institutions do not have any data repository. Most of the discussions surrounding open data have also excluded scientific and research data. Recently, one of the states in India, Telangana, released their Open Data Policy. ${ }^{104}$ However, even this policy failed to explicitly include within its ambit research related data. ${ }^{105}$

To summarise, India is one of the countries which is facing challenges in implementation of open science. It is yet to see a sustainable and strong open science initiative, which meets all the characteristics of our definition of open science. ${ }^{106}$ This also highlights the need for identifying localised solutions for fuelling an open science movement in India.

\section{IPR Policy/ Legal Changes to Support Open Science}

The previous sections highlight the need for a stronger and sustainable open science movement in India. It is important to analyse, in this context, the IP related legal and policy measures that may help in fostering the open science movements in India. While there are many institutional

\footnotetext{
${ }^{101}$ National Data Sharing and Accessibility Policy 2012 <http://ogpl.gov.in/NDSAP/NDSAP-30Jan2012.pdf〉 accessed on 17 September 2016.

102 Ibid cl 1.2.

${ }^{103}$ Ibid cl 1.3.

104 Telangana Open Data Policy 2016 <http://www.it.telangana.gov.in/telangana-open-data-policy-2016/> accessed on 17 September 2016.

${ }^{105}$ For the comments we had submitted, highlighting the importance of including research data under the Telangana Open Data Policy 2016, see <https://drive.google.com/file/u/1/d/0B3AFErneilW0eWFhUXVnbWRndnE0U1ppeHdPNXpsSGF5UzBz/view?usp $=$ drivesdk $>$ accessed on 17 September 2016.

${ }^{106}$ However, some of the other researchers who have tried to map the open science movements in India have reached a different conclusion by looking only at certain aspects of open science. For example the Innovation Policy Platform has mapped the various government 'open science' initiatives. The Innovation Policy Platform, 'India: Open Science Country Note' $<$ https://www.innovationpolicyplatform.org/printpdf/19856> accessed on 19 September 2016.
} 
and systemic changes required to achieve the goal of fostering innovation and development through open science, we have identified three areas where changes in the way we approach IP may help in achieving open science goals: First, changes in the view taken by India with regard to the role of IPRs in promoting innovations; second, changes in the current copyright law to promote activities like text and data mining (TDM); and third, the need for developing mandatory guidelines from the side of funding agencies to limit exercise of IP over certain research outputs.

How countries view the role of IPRs in the broader innovation eco-system may influence the country's approach towards open science. Recently, India released a national IP policy, outlining the strategies the country will adopt in the area of IPRs for stimulating innovations and creativity ${ }^{107}$ Unfortunately, the policy appears to have been misguided by the myth that stronger protection and enforcement of IPRs and individual rights are the only paths to more innovation. ${ }^{108}$ It ignores many of the recent data and literature which challenge the traditional notions of the role of IP in stimulating innovations and creativity. ${ }^{109}$ At many places, it even considers the creation of IPRs as an end in itself, rather than as just one of the components of the broader innovation eco-system. ${ }^{110}$ An unfortunate result of this approach is also the total neglect of the role of open science in promoting innovations.

\footnotetext{
${ }^{107}$ National Intellectual Property Rights Policy 2016 <http://dipp.nic.in/English/Schemes/Intellectual_Property_Rights/National_IPR_Policy_08.08.2016.pdf > accessed on 19 September 2016.

${ }^{108}$ Shamnad Basheer, 'An IP Policy with No Innovation' The Hindu (17 May 2016) $<$ http://www.thehindu.com/opinion/op-ed/intellectual-property-an-ip-policy-with-noinnovation/article8607910.ece> accessed 18 September 2016; KM Gopakumar, 'Why New IPR Policy Is Inadequate' (2016) 51 Economic and Political Weekly 16, 16-18; and Anubha Sinha, 'Modi's New Intellectual Property Rights Policy Will Only Benefit Players with Deep Pockets' < http://thewire.in/37567/the-new-intellectualproperty-rights-policy-will-only-benefit-players-with-deep-pockets-and-great-power/> (The Wire, 21 May 2016) accessed 18 September 2016.

${ }^{109}$ See generally, The Economist, 'A Question of Utility' (The Economist, 8 August 2015) $<$ http://www.economist.com/node/21660559> accessed 18 September 2016; The Economist, 'Time to Fix Patents' (The Economist, 8 August 2015) <http://www.economist.com/news/leaders/21660522-ideas-fuel-economy-todayspatent-systems-are-rotten-way-rewarding-them-time-fix > accessed 20 September 2016; Mark A Lemley, 'IP in a World without Scarcity' (2015) 90 NYU Law Review 460; and Mark A Lemley, 'Faith-Based Intellectual Property' (2015) 62 UCLA Law Review 1328.

${ }^{110}$ For example, this is even evident in the Vision Statement of the Policy, which starts with the statement " $[a] n$ India where creativity and innovation are stimulated by Intellectual Property for the benefit of all; an India where intellectual property promotes advancement in science and technology, arts and culture, traditional knowledge and biodiversity resources...” See National Intellectual Property Rights Policy 2016, 1. See, also, Shamnad Basheer, 'An IP Policy with No Innovation'.
} 
It is interesting to note that the national IP policy uses the term 'open' only at three places in 26 pages document. At one of those three places, the policy mentions that steps will be taken to "[e]ncourage R\&D including open source based research such as Open Source Drug Discovery (OSDD) by the Council of Scientific and Industrial Research (CSIR) for new inventions for prevention, diagnosis and treatment of diseases, especially those that are life threatening and those that have high incidence in India." 111 However, the policy does not provide any further information on how and when open source based research will be promoted. One may contrast this with the approach taken by the policy with regard to generating and enforcing diverse IPRs, wherein it has gone into extensive details of implementation strategies. ${ }^{112}$ It is also interesting to note that the only field of research that the policy envisages open source based approaches is medical research, whereas open approaches can have diverse beneficial effects in many other areas too.

In another part of the document, the policy mentions that steps will be taken to "[p]romote 'infusion of funds to public R\&D units' as a part of Corporate Social Responsibility to foster a culture of open innovation." 113 While the policy doesn't mention anywhere what it means by culture of open innovation, it is even more problematic to see it just as an activity which is part of corporate social responsibility of public R\&D units. As many scholars have pointed out, open innovation is one of the most important strategies adopted today by firms for fostering innovations in many areas. ${ }^{114}$ However, the approach taken by the policy to promote it just as part of CSR activities of public R\&D units illustrate the clear lack of understanding of the nature and importance of open innovation.

The national IP policy uses 'open' for the third time when it highlights the need to " $[p]$ romote use of Free and Open Source Software along with adoption of open standards."115 Unfortunately, here also the policy doesn't provide any concrete guidelines as to the measures that will be taken for promoting use of free and open source software.

In this context, we need to clarify that open science is not against IPRs per se. As highlighted by many scholars, both open science and IPRs can co-exist. ${ }^{116}$ But IPRs beyond its reasonable limits

\footnotetext{
${ }^{111}$ National Intellectual Property Rights Policy 2016, cl 2.10.

${ }^{112}$ See, for example, the detailed clauses under objectives 1, 2, 4, 5, and 6 of the Policy. National Intellectual Property Rights Policy 2016, 5-10 and 14-17.

${ }^{113}$ National Intellectual Property Rights Policy 2016, cl 2.17.

${ }^{114}$ See, for example, Henry Chesbrough, Wim Vanhaverbeke and Joel West, Open Innovation: Researching a New Paradigm (Oxford University Press 2008).

${ }^{115}$ National Intellectual Property Rights Policy 2016, cl 5.12.

${ }^{116}$ Interview with Subbiah Arunachalam.
} 
can certainly be detrimental to open science. ${ }^{117}$ Restrictions based on copyright law can prevent dissemination of educational and research materials. For example, some of the leading publishers had initiated copyright infringement litigation against the University of Delhi to prevent dissemination of course related materials. ${ }^{118}$ While IPRs may be one of the numerous components in the broader innovation eco-system, they should not be allowed to restrict openness in research.

It is also pertinent to note that many of the major open movements like Creative Commons rely on the existing intellectual property framework to promote open approaches. Creative Commons uses the copyright law framework to promote access to creative works. ${ }^{119}$ Similarly, the technology commons approach, advocated by Anil K. Gupta and the Honeybee Network, is trying to promote more horizontal sharing of information within the boundaries of the current IP system. ${ }^{120}$ But by projecting stronger protection and enforcement of IPRs as the only solution for more innovations, the Indian policy makers are ignoring the importance of openness in the development of a stronger innovation eco-system in India.

A balanced copyright regime that supports openness is extremely important. India has a copyright statute with fairly broad set of exceptions. ${ }^{121}$ It follows the hybrid approach that combines a relatively broad fair dealing exception with a set of enumerated exceptions. ${ }^{122}$ However, India doesn't have a specific exception for Text and Data Mining (TDM). The term 'text and data mining' generally refers to "use of automated analytical techniques to analyse text and data for patterns, trends and other useful information". ${ }^{23}$ TDM allows researchers to analyse large amounts of data digitally, which would otherwise require enormous manual efforts. ${ }^{124}$ However, TDM is impossible without at least the temporary reproduction of the work that is analysed. In the absence of a specific exception, researchers face copyright infringement

\footnotetext{
${ }^{117}$ Interview with Shamnad Basheer and interview with Jayant Murthy.

${ }^{118}$ However, the Delhi High Court has ruled in favour of the University. See The Chancellor, Masters \& Scholars of the University of Oxford and others v. Rameshwari Photocopy Services and another, [2016] CS(OS) 2439/2012 <http://lobis.nic.in/ddir/dhc/RSE/judgement/16-09-2016/RSE16092016S24392012.pdf> accessed 16 September 2016.

119 <https://creativecommons.org/faq/\#is-creative-commons-against-copyright> accessed 18 September 2016.

120 'Questions and Answers: Prof. Anil Kumar Gupta' Wall Street Journal (24 September 2009) <http://www.wsj.com/articles/SB125376926792036847> accessed 18 September 2016.

${ }^{121}$ See Copyright Act 1957, s 52.

122 Ibid.

123 'Exceptions to Copyright - Detailed Guidance' < https://www.gov.uk/guidance/exceptions-to-copyright\#text-anddata-mining-for-non-commercial-research> accessed 18 September 2016.

${ }^{124}$ Declan Butler, 'Europe Proposes Copyright Reform to Help Scientists Mine Research Papers' Nature (15 September 2016) <http://www.nature.com/doifinder/10.1038/nature.2016.20606> accessed 18 September 2016.
} 
related liabilities whenever they engage in TDM of a copyrighted work. This in turn would negatively affect the enormous research possibilities of TDM. The United Kingdom is one of the countries having a specific data mining exception. ${ }^{125}$ The UK Copyright law allows researchers to make copies of any work protected under it for the purpose of TDM, as long as they have lawful access to the work. ${ }^{126}$ The exception in this regard applies to TDM for any noncommercial research. ${ }^{127}$ The most important implication of such an exception is that publishers will not be able to impose or enforce contract terms that restrict researchers from making copies of articles for the purpose of TDM. ${ }^{128}$ Addition of a similar exception to the Indian Copyright Act can provide the much needed legal clarity and certainty for TDM in India.

Finally, it is important to acknowledge the unique position of funding agencies in fostering the open science movement. Funding agencies can play a major role in curtailing the misuse of IPRs by researchers to prevent openness. They can achieve this by limiting the scope of IPRs over certain research outputs like articles and research data. This includes making mandatory obligations on the researchers to share those research outputs through open access modes.

State supported funding agencies, in particular, should ensure that the research funded by them is accessible to the public. ${ }^{129}$ Unfortunately, in India dissemination is still not seen as a priority. ${ }^{130}$ However, in countries like the United States, some of the funding agencies mandate open access. For example, the National Science Foundation (NSF) and the National Institutes of Health (NIH), two of the most prominent funding agencies, have specific policies in this regard. The NSF guidelines mandate that the version of record or the final accepted version of the manuscript must be deposited in a repository no later than a year after the initial publication. ${ }^{131}$ Similarly, NIH mandates that the final peer-reviewed manuscripts should be submitted to the digital archive, PubMed Central. ${ }^{132}$ Even private funding agencies such as the Wellcome Trust in the

\footnotetext{
${ }^{125}$ Copyright, Designs and Patents Act 1988 (CDPA), s 29A.

126 Ibid.

127 Ibid.

128 Ibid, s29 (5).

129 Peter Suber, 'The Taxpayer Argument for Open Access'

$<$ https://dash.harvard.edu/bitstream/handle/1/4725013/suber_taxpayer.htm?sequence=1> accessed 19 September

2016.

${ }^{130}$ Interview with Anil K Gupta.

${ }^{131}$ NSF's Public Access Plan: Today's Data, Tomorrow's Discoveries 2015, cl 3.1

<http://www.nsf.gov/pubs/2015/nsf15052/nsf15052.pdf> accessed on September 192016.

132 Public Access Policy Details 2008 <http://publicaccess.nih.gov/policy.htm> accessed 18 September 2016.
} 
United Kingdom have made it mandatory for projects to release research outputs through open access modes. ${ }^{133}$

Unfortunately, in India, even when the funding agencies mandate open access, they do not put any enforcement mechanisms in place. ${ }^{134}$ With no clear guidelines or monitoring mechanisms, the compliance may remain poor. In this regard, it is also interesting to note that during the initial years, when the NIH policy was voluntary, the compliance rate was at a mere $4 \%{ }^{135}$ In a country like India, which spends enormous sums of public money on research, it is extremely important to ensure compliance with the policies, and with no monitoring mechanisms in place, their objectives may remain unfulfilled. ${ }^{136}$

Before we conclude, we must also add that some scholars are of the view that legal and policy measures alone will not make the necessary changes. For example, according to Murali Mohan, who heads the Big Data Initiative of the Government of India, laws won't make a difference unless accompanied by changes in ethical values. ${ }^{137}$ Laws are not the primary tool preventing people from sharing. ${ }^{138}$ More studies need to be conducted for identifying the factors that dissuade people from practicing open science, and for identifying the incentives that may promote open science. ${ }^{139}$

\section{Conclusion}

Open science is a global movement aimed at restoring the core tenets of science. Its implications are far reaching and go beyond the scientific research eco-system. It can play an important role in democratising science. While we need to acknowledge the existence of certain challenges in its implementation, as the paper highlights, the benefits outweigh the challenges involved. Open science can be particularly helpful for countries in the global south to achieve optimal use of

\footnotetext{
${ }^{133}$ Open Access Policy <https://wellcome.ac.uk/funding/managing-grant/open-access-policy>accessed 18 September 2016.

${ }^{134}$ See for example, 'DST and DBT Open Access Policy'.

135 Peter Suber 'An Open Access Mandate for the National Institutes of Health' (2008) 2 Open Medicine e39 14,14.

${ }^{136}$ See 'Budget 2015: Boost for Science \& Technology as Government Allocates Rs 7,288 Crore for Research' The Economic Times (28 February 2015) <http://economictimes.indiatimes.com/news/economy/finance/budget-2015boost-for-science-technology-as-government-allocates-rs-7288-crore-for-research/articleshow/46413572.cms> accessed 17 September 2016.

${ }^{137}$ Interview with Murali Mohan, Head and Scientist, Big Data Initiatives Division, Department of Science \& Technology (New Delhi, 2 August 2016).

${ }^{138}$ Interview with Jayant Murthy and interview with Zakir Thomas.

${ }^{139}$ As part of a project on open science, the Centre for Innovation, Intellectual Property and Competition (CIIPC), is conducting a survey amongst researchers, focussing on this aspect. <ciipc.org/open-science-for-an-innovativeindia> accessed 20 September 2016.
} 
scarce resources and address the inequalities in the global knowledge sharing. However this requires changes in the way many countries perceive the role of IPRs in the broader context of research and innovation. The policy suggestions made in this paper in the context of India, are examples of how countries may modify certain aspects of their IPs system to embrace open science. However, for any movement to be successful, the focus should primarily be on the key stakeholders. In the context of open science movements, more individual level studies need to done to map the factors that dissuade researchers from participating in the open science movement. Identification of those factors will help in formulating better incentives for practicing open science. Through such a holistic approach we will be able to regain the true values of science and may even make the prefix 'open' redundant. 